\title{
Presenting a Model of Interpretive Structural Method in Order to Rank the Strategic Factors on the Development of Foreign Trade Studied in Iran-Iraq Trade
}

\author{
Mojtaba Rostami \\ Department of Business Management, Faculty of Humanities, Islamic Azad University, Hamadan Branch, Iran
}

Email address:

rostami.mojtaba@yahoo.com

\section{To cite this article:}

Mojtaba Rostami. Presenting a Model of Interpretive Structural Method in Order to Rank the Strategic Factors on the Development of Foreign Trade Studied in Iran-Iraq Trade. Mathematics Letters. Vol. 6, No. 4, 2020, pp. 42-50. doi: 10.11648/j.ml.20200604.11

Received: September 17, 2020; Accepted: October 27, 2020; Published: December 31, 2020

\begin{abstract}
The environment in foreign trade is dynamic and complex. Today, the promotion and development of foreign trade requires the adoption of newer strategies. Iran's location in West Asia and having valuable mineral resources has a strategic position. In this study to design a structural model The purpose of this article is to identify the governing factors necessary for the realization of Iran's foreign trade in the region, to examine the relationship between them and to prioritize them for its importance. A set of new strategies And effectively obtained from a complete review of the literature and opinions of 10 experts. Then content-related relationships were selected for each pair. In addition, a hierarchical interpretive structural model was created using a structural interpretive technique. The findings of this study classify the effective factors based on driving power, influence and dependence. The findings show that knowledge-based economy is the underlying factor and the import substitution variable is one of the most dependent factors of the ISM model. These economic agreements as a model variable relationship with the impact Ray and susceptibility with high penetration and dependence, can be the intersection between other components of the model.
\end{abstract}

Keywords: Foreign Trade, Strategic, Iran, Interpretive Structural Model, ISM

\section{Introduction}

Due to advances in production and information technology, countries are now changing the way international business and foreign trade improvements. Foreign trade as a vital cause of economic growth plays an important role in optimizing global resource allocation and growth. Due to the growing global economy and regional economic cooperation, trade dependence between countries has increased, which will lead to a joint movement of regional economies and foreign trade. As a result, it makes sense to monitor the volatility of foreign trade cycles. In the 2017 Mackenzie report, the long-term future of global trade will change with technical changes and changes in international trade policy. Today, the world is seeking a balance. The change in the role of some sectors of the economy is the emergence of a new model for international trade and a rethinking of the role of inequality in the economic and social development of leading countries [28]. However, it is clear that the main issue in political and intellectual programs, it is a new model of economic growth and its potential rate and resources [28]. One of the most theoretical ideas in the field of economics is to use the capacity of foreign trade to create economic growth [6]. According to the World Bank, Iran's GDP growth has been declining in the return of 2017-2011. The economic growth rate has always been fluctuating, the lowest rate in 2013 with a decrease of 7.4 percent and the highest rate in 2016 with 13.4 percent In 2017, Iran's economic growth rate was announced at 4.3 percent. The declining trend of GDP, in other words, indicates a decrease in production and lack of use of economic capacity. Existing research gaps were identified as the need for studies due to the lack of comprehensive dimensions and components for the development of Iran's foreign trade sector, as well as the formation of new and emerging phenomena in the world economy. Gaps in Iran's economic structure depend on oil revenues and the oil economy has become a factor in not using export and economic capacities in the region (15 
neighboring countries).

Due to the emergence of economic or political crises affecting not only the country, but also its neighbors and partners who have any kind of relationship, it is imperative that countries should analyze their foreign trade performance and export strategies. For companies as a success in a competitive business environment [8]. Literature There is a lot of topic that explains the strategies and strategies needed to implement in the foreign trade system, but the literature At present, solutions to problems related to new strategies and deterrents in Iran's trade relations with countries in the region and resource prioritization have not been provided. Based on the existing literature, this study is to identify the effective components and show the interaction between them. In addition, the study incorporates an interpretive structural model that combines all factors, along with interactions with other components, to provide insights and suggestions to managers. So that countries can prioritize their resources and efforts. And is active in the field of foreign trade. The rest of the article is as follows. Highlights relevance to new and effective factors and strategies, and then provides a brief description of the components. The research method is then discussed, including an overview of structural interpretive modeling (ISM). This paper develops a structural model based on ISM techniques and classifies components into four different levels based on their penetration power and dependence.

\section{Theoretical Foundations of Research}

\subsection{Foreign Business}

Foreign trade is one of the main factors of economic growth [4]. International trade is another important tool to facilitate the development of technology and economic growth as the main factors of performance growth. Use various types of technologically advanced physical capital to increase resource productivity [34]. China's economic reform process, such as increased productivity and trade reform, has led to rapid economic growth, which reflects the opening up of the economy. According to the Trade Map website, in 2018, China's world-ranked exports reached \$ 2.494 billion, accounting for $13 \%$ of world exports. Economic development is crucial for the sustainable growth of any society [19].

Iran shares a land border with seven countries: Iraq, Turkey, Pakistan, Afghanistan, Azerbaijan, Turkmenistan, and Armenia, which according to the latest world population statistics have a total population of 450 million, including Iran, while Pakistan is the sixth most populous country. The Keynesian World Institute predicts that by 2025, the world economic center of gravity will be on the Indo-Chinese border, creating the potential for Iran to act as an East-West link. In launching the New Realities of Global Trade 2017, McKenzie predicts that the long-term future of trade is driven by major global changes, including rapid urbanization, rising middle-class consumers in emerging economies, geopolitical complexities, and changing trends. International finance is formed. However, the two disciplines are changing due to uncertainty about their future effects, including changing technical conditions and changing environmental-international policy policies. Changing technologies continue to have a profound impact on the speed and composition of trade growth. [36].

\subsection{Background Research}

The literature review summarizes the study of influencing factors and foreign trade policies in 14 variables. The influencing factors of new strategies are presented as follows.

1. Knowledge-Based Economics (KBE)

The OECD defined the knowledge-based economy as "independent based on the production, distribution and use of knowledge and information. In other words, in an economy, knowledge plays a key role as the main engine of economic growth. According to the Asia-Pacific Economic Cooperation (APEC) report, the knowledge-based economy has the following characteristics: 1) general innovation and technological change, 2) effective support for national innovative systems (ie, intergovernmental networks) And privately formed and new technology / methods are created and disseminated through network interactions) 3) continuous development of human resources and 4) a business environment that is based on companies and their innovations based on effective infrastructure through which individuals and companies can easily access [24]. Currently, the economies of developed countries are based on knowledge and information and are therefore known as the knowledge economy. The performance of developed countries depends on the creation, distribution and use of related knowledge and information. Information and knowledge as the main and most productive source of wealth creation Are considered [38].

2. Effective Structural Change (ESC)

The force of economic growth and development is inherently related to changes in the structure of economic activity. Although the concepts of structural change are defined in different ways, the most common means long-term and sustainable changes in the composition of various parts of economic systems. The main features of economic growth are a sustainable increase in production growth and factor productivity and a process. According to the United Nations Industrial Development Organization (UNIDO), structural change is the "different mechanisms of productive activity in the economy and the different distribution of factors of production between different sectors and professions, geographical areas". "Types of products, etc." According to UNIDO (2010), structural changes occur in three important ways, including: "Transfer of labor from less productive sectors to higher productivity sectors" "Transfer of capital through an increase in the proportion Capital to Labor" and "Technology Improvement by Increasing Total Productivity of Production Factors. "From the findings of Vu (2017) [44], the paper introduces a new measure of structural change called "effective restructuring "(ESC), which 
Capturing the effectiveness of labor change across sectors leads to an increase in total labor productivity. Structural change has a significant impact on labor productivity growth, TFP, GDP per capita, GDP and wages [16].

3. Trade Openness (OUT)

Open trade and finance can facilitate access to essential inputs, especially through the transfer of valuable skills and innovation for industrial development. This, in turn, can be accompanied by diversification of production and exports, and As a result, it creates lower structural vulnerabilities. Trade openness can improve export opportunities by increasing the number of exporters in those countries [14]. Developed countries (with better institutions and higher worker productivity) and Developing countries also specialize in more complex areas. Vietnam has made significant economic reforms related to two issues: (1) rebuilding the domestic economy; And (2) the opening of the economy to foreign trade and investment, which has led to the growth of GDP, developed its diplomatic and foreign investment relations with the countries of the region and provided export capacities [34].

4. Economic Endogeneity (EE)

The growth of the productive sector is essential for economic development and increased productivity, especially in middle-income countries. Investing in specific industries creates the effects of linkages and learning processes that increase production growth and residual productivity of the production structure. Be. Exports of industrial goods stimulate domestic demand, the learning process with productivity, increase productivity and develop new comparative benefits [30]. Industrialization continues to play a major role in the growth of developing countries. They have continued to grow rapidly and long-term over the past 25 years. Achieving economic progress by following the path of industrialization is likely to continue to be important for low-income countries [17]. Agriculture contributes to GDP. The production sector accounts for a significant share of economic growth [39].

5. Institutional Gap (IG)

Institutions are the rules of the game in a society. Institutions create a framework that facilitates economic transactions and thus reduces uncertainty. Therefore, the security of international exchanges depends on the strength of institutions. Inefficient institutions can Stop Trade: Corruption, insufficient information on international trade opportunities, and incomplete contract implementation significantly increase transaction costs associated with international trade [20, 27]. According to research by Márquez et al. (2012), tariff barriers to trade are just one of the factors that drive trade costs. Due to the declining impact of tariff barriers on the overall process of trade, institutional barriers have become relatively more important and have become a major barrier to the flow of goods between countries. [27, 32]. a country with quality institutions in addition to lower production costs, Exchange costs will be lower. An improvement in the quality of the exporting country's institutions will increase the complex exports of that country [32]

6. Small and Medium Industries (SMEs)

Today, small and medium industries are one of the most important sectors in the economic and social system, so that the countries of the world are surpassing each other in terms of the number of small and medium industrial companies. According to the Economic Cooperation Development Organization, most industrialized countries More than 96\% of all construction companies and manufacturing sector are composed of small and medium industries and are among the main areas of employment [2]. With the advancement of science and technology, the demand for high quality of life gradually Has increased, thus the use of resources for production and consumption is significant. SME participation in sustainable strategy development is inevitable [7].

7. Financial and Credit Restrictions (FCS)

Following the necessary structural reforms in the banking sector around the world, the relationship between banking centrality and financial constraints has recently attracted considerable attention among researchers [3]. In economies with high capital constraints, bank development Can reduce capital shortages and promote entrepreneurial measures to strengthen new industries Development banks are an important tool for addressing market shortages [11]. Entrepreneurial gaps face financial constraints. The financial gap may change over time. Entrepreneurship gaps may change over time. They are growing to the point that they need a significant amount of funds to realize the potential growth of primary income generation [43].

8. Trade in Value-Added (TiVA)

According to the Organization for Economic Co-operation and Development (OECD), the development of value-added trade (TiVA) takes into account the value added of each country in the production of goods and services consumed around the world. Global value chain is a topic that has attracted the attention of many researchers and policy communities in the last two decades. All activities related to the flow of goods and conversion of materials, from the preparation of raw materials to the delivery of final goods to consumers in the field of value chain [25]. The diversity of trade and exports is important in recent analysis. The organizational, macroeconomic, trade, and industrial policies required for successful global value chain participation are important. Can stop the recession among middle-income countries [42]. In addition, industrial diversity must move towards upgrading or increasing complexity, which is considered as a strategy in which Countries, companies and actors are looking to move from low value-added to value-added activities [30].

9. Import Substitution

Between the 1950s and 1980s, Latin American countries pursued import substitution (IS) as a development strategy. A set of policies was implemented to develop the domestic manufacturing sector. An important element of the IS strategy was the level of Provide high support for domestic producers [35]. A look at the economic history and the study of various 
international trade trends, it is easy to see that the introverted strategy relies on the internal strength of countries. Countries that choose this policy, using a variety of protections and tariff and non-tariff restrictions, limit their imports and insist on producing similar foreign goods. With the continuation of this process, countries need value to build their final product and assembly. Among the introverted policies, we can mention the strategy of import substitution [1]. Import substitution policy is associated with increasing profits in the domestic industry. Sustainable economic development of countries is possible only based on increasing the level of industrial self-sufficiency and increasing production. Industrial alternative import is a tool to improve national economic competition and ensure the country's economic security [12].

10. Trade Facilitation (TF)

According to the USAID definition, trade facilitation means harmonized, transparent, and internationally accepted standards, rules, and procedures to facilitate the international movement of goods and services and to reduce non-tariff barriers to the expansion of trade. Trade facilitation is considered as one of the key factors for the economic development of different countries. The strategic goals of the WCO are to improve security and facilitate international trade, including the simplification and coordination of customs procedures. There are a variety of business costs that can have business effects based on transaction costs [9]. Indicators have been used to measure four areas of trade facilitation, namely port productivity, customs environment, regulatory environment, and service sector infrastructure [33].

11. Trade Costs

The World Bank (2017) report addresses trade costs. One of the most important barriers for developing countries is trade costs. Today, non-tariff trade costs (transportation, insurance, and other cross-border costs) are much higher than Tariffs and tariff barriers prevent countries from operating globally. Commercial costs that vary from country to country and sector to sector, in addition to monetary dimensions (such as transportation, insurance, and other costs), have other costs that are imperceptible, including information costs, non-monetary barriers (regulations, licensing, and Etc.), unsafe and weak administrative-commercial contracts that lead to uncertainty. These trade barriers can be much more problematic than tariff barriers. World Bank investment surveys show that heavy licensing processes, complex regulations, inadequate bidding procedures, time and financial costs are major regulatory and administrative barriers to doing business. Is work [20].

12. Foreign Direct Investment (FDI)

In the last decade, FDI has been a vital issue for emerging markets [31]. FDI foreign direct investment has been an important issue for developing countries; Because economic development brings with it access to managerial skills, financial resources, marketing expertise, and leads to increased employment [23]. Significant reduction in FDI outflows from developing countries in the context of two important program discussions International development takes place: one; How to revitalize trade is multifaceted, and second, how to manage (or deal with) macroeconomic vulnerabilities, including structural vulnerabilities that developing countries face. Structural economic vulnerability prevents resource use Various (including technical knowledge, technology and management experience) are involved with the involvement of companies in internationalization through foreign direct investment from developing countries [15].

13. Economic Cooperation Agreement (ECA)

Since 2003, as the number of interregional trade agreements has increased, cooperation between the two regions has increased unprecedentedly. Asian and Latin American countries have ratified 18 bilateral free trade agreements. One of the distinctive features of these agreements is that their scope extends beyond the traditional coverage of trade in goods. Trade and investment flows between the two regions have also increased in recent years [5]. Vietnam is seriously pursuing its FTA policy. Of the 16 FTA agreements, including the negotiators, eight include ASEAN. The rest are regional agreements. Including Regional Trade Agreements (RTAs), Comprehensive and Leading International Transport Cooperation (CPTPP), Comprehensive Regional Economic Cooperation (RCEP), EU-Vietnam Free Trade Agreement (EVFTA), Foreign Direct Investment Flow Vietnam reached \$ 24.4 billion in 2016. ASEAN has been the largest source of foreign direct investment for Vietnam [22].

14. Free Trade Zones (FTZs)

Free Trade Zones (FTZs) are rapidly evolving in the face of the fact that FTZs have become a platform and measure for every country in the world to strengthen foreign economic cooperation, expand international trade, attract foreign investment and reduce trade disputes. The benefits of FTZs in foreign trade policies give companies opportunities to internationalize, outsource outsourcing, and disseminate knowledge and technology. On the other hand, corporate aggregation and coordinated development are possible. Make changes in organizational structure and organizational relationships, such as companies that are in organizational groups and strategic alliances, so that the foundations of technology and knowledge sharing among companies and improve organizational performance can be established. [37]. The expansion of trade in the free zones, in terms of scope and intensity, is very significant and the openness of the zones due to exports to GDP is one of the highest in the country. And considers compatibility [35]. 
Table 1. Factors affecting the foreign trade model based on the findings of the literature.

\begin{tabular}{lll}
\hline & Variables & References \\
\hline 1 & Knowledge-based economy & {$[24,38]$} \\
2 & Effective structural change & {$[44,16]$} \\
3 & Trade openness & {$[14,34]$} \\
4 & Endogenous & {$[30,17]$} \\
5 & Institutional gap & {$[20,27]$} \\
6 & Small and medium industries & {$[17,2]$} \\
7 & Financial and credit constraints & {$[3,43]$} \\
8 & Value added trade & {$[42,25]$} \\
9 & Import substitution & {$[35,12]$} \\
10 & Facilitate trade & {$[9,33]$} \\
11 & Commercial costs & {$[20]$} \\
12 & Foreign direct investment & {$[15,31]$} \\
13 & Regional economic agreements & {$[21,22]$} \\
14 & Free trade zones & {$[37,34]$} \\
\hline
\end{tabular}

\section{Research Methodology}

Interpretive Structural Model (ISM) was first proposed by Warfield in 1974. It is one of the tools of interactive management. It transforms vague and incomprehensible mental models of a system into observable, well-defined, and hierarchical models. It is a method of analyzing and solving complex problems for decision management [10].

Interpretive Structural Modeling (ISM) is an interactive learning process. It is an interpretive approach while group judgment decides which factors and how are related; Based on the relation, a general structure is extracted from a set of variables; And its modeling is that specific relationships and general structure are shown in a model [29]. The main idea of interpretive structural modeling is to break down a complex system into several subsystems (elements) using practical experience and expertise of experts in order to build a multi-level structural model [40]. By snowball sampling, 10 people with data saturation were selected. Data were obtained through a matrix questionnaire describing the method. Based on the seven steps of ISM methodology was performed as follows [42].

\section{Interpretive Structural Modeling Approach for Factor Modeling}

\subsection{Factor Identification Step}

During the study, the literature on new strategies in foreign trade was thoroughly reviewed, which led to the identification of 14 key factors. Details of these factors are given in Table 1.

\subsection{Structural Interactive Matrix Formation (SSIM)}

Once identified and implemented, the need for analysis should be analyzed when assigning a specific relationship to each pair. Is discussed.

Table 2. Structural self-interaction matrix.

\begin{tabular}{|c|c|c|c|c|c|c|c|c|c|c|c|c|c|c|}
\hline Variables & 1 & 2 & 3 & 4 & 5 & 6 & 7 & 8 & 9 & 10 & 11 & 12 & 13 & 14 \\
\hline Knowledge-based economy & & $\mathrm{A}$ & $\mathrm{O}$ & $\mathrm{X}$ & $\mathrm{X}$ & $\mathrm{A}$ & $X$ & $\mathrm{X}$ & $\mathrm{V}$ & $\mathrm{V}$ & $\mathrm{X}$ & $\mathrm{X}$ & $\mathrm{X}$ & $\mathrm{X}$ \\
\hline Effective structural change & & & V & $\mathrm{X}$ & $\mathrm{V}$ & A & A & $\mathrm{V}$ & $\mathrm{V}$ & $\mathrm{O}$ & $\mathrm{V}$ & $\mathrm{O}$ & $\mathrm{X}$ & A \\
\hline Trade openness & & & & $\mathrm{O}$ & A & $\mathrm{V}$ & $\mathrm{X}$ & $\mathrm{V}$ & $\mathrm{O}$ & $\mathrm{X}$ & $\mathrm{V}$ & $\mathrm{X}$ & $\mathrm{X}$ & $\mathrm{X}$ \\
\hline Endogenous & & & & & $\mathrm{O}$ & $\mathrm{X}$ & A & $\mathrm{X}$ & $\mathrm{V}$ & $\mathrm{O}$ & $\mathrm{O}$ & V & $\mathrm{V}$ & $\mathrm{O}$ \\
\hline Institutional gap & & & & & & A & $\mathrm{O}$ & $\mathrm{X}$ & $\mathrm{O}$ & A & $\mathrm{O}$ & $\mathrm{X}$ & $\mathrm{O}$ & $\mathrm{X}$ \\
\hline Small and medium industries & & & & & & & $\mathrm{O}$ & $\mathrm{X}$ & $\mathrm{V}$ & A & A & $\mathrm{X}$ & $\mathrm{O}$ & $\mathrm{O}$ \\
\hline Financial and credit constraints & & & & & & & & $\mathrm{V}$ & $\mathrm{O}$ & $\mathrm{X}$ & A & $\mathrm{O}$ & $\mathrm{V}$ & $\mathrm{O}$ \\
\hline Import substitution & & & & & & & & & & $\mathrm{O}$ & $\mathrm{O}$ & $\mathrm{O}$ & $\mathrm{X}$ & $\mathrm{X}$ \\
\hline Facilitate trade & & & & & & & & & & & $\mathrm{O}$ & $\mathrm{X}$ & A & $\mathrm{X}$ \\
\hline Commercial costs & & & & & & & & & & & & A & A & A \\
\hline Foreign direct investment & & & & & & & & & & & & & A & A \\
\hline Regional economic agreements & & & & & & & & & & & & & & $\mathrm{X}$ \\
\hline Free trade zones & & & & & & & & & & & & & & \\
\hline
\end{tabular}

\subsection{Initial Access Matrix (RM)}

At this stage, the achievement matrix (RM) of the self-interactive matrix (SSIM) has been developed. The format is initially converted to a primary matrix format by converting the information of each cell of the self-interacting matrix to a binary digit (1-0).

\subsection{Final Achievement Matrix}

Once the initial access matrix has been obtained, its internal consistency must be established. Such that if $(i, j)$ are related and $(\mathrm{j}, \mathrm{k})$ are related; Then $(\mathrm{i}, \mathrm{k})$ are related [18]. In this matrix, the influence and degree of dependence of each variable is also shown. 


\subsection{Determining the Level of Variables and Forming a Matrix}

From the final achievement matrix, the achievement set and the preliminary set are derived for each of the factors [13]. Determine the direction of each of the elements of the matrix. The different levels are presented in Table 3.

Table 3. Leveling of indicators.

\begin{tabular}{|c|c|c|c|c|c|c|c|}
\hline & Input variables & Output variables & Common & frequency & Level & infiltrate & Dependence \\
\hline 1 & $1,2,4,5,6,6,7,8,11,12,13,14$ & $1,3,4,5,6,6,7,8,9,10,11,12,13,14$ & $1,4,5,6,6,7,8,11,12,13,14$ & 23 & 9 & 13 & 10 \\
\hline 2 & $2,4,6,6,7,13,14$ & $1,2,3,4,5,6,6,8,9,10,11,12,13,14$ & $2,4,6,613,14$ & 19 & 7 & 13 & 6 \\
\hline 3 & $1,2,3,5,7,710,12,13,14$ & $3,6,7,8,9,10,11,12,13,14$ & $3,7,10,11,12,13,14$ & 17 & 5 & 10 & 9 \\
\hline 4 & $1,2,4,4,6,7,8$ & $1,2,4,6,7,7,8,9,10,12,13,14$ & $1,2,4,4,6,7,8$ & 17 & 5 & 11 & 6 \\
\hline 5 & $1,2,5,6,6,8,10,12,14$ & $1,3,5,5,8,9,12,13,14$ & $1,5,5,8,12,14$ & 13 & 3 & 8 & 8 \\
\hline 6 & $1,2,3,4,6,6,8,10,11,12$ & $1,2,4,5,6,6,8,9,12,13,14$ & $1,2,4,4,6,8,12$ & 16 & 4 & 10 & 9 \\
\hline 7 & $1,3,4,7,7,10,11$ & $1,2,3,4,7,7,8,9,10,11,13,14$ & $1,3,4,7,7,10,11$ & 17 & 5 & 11 & 6 \\
\hline 8 & $1,2,3,4,5,6,6,7,8,9,10,12,13,14$ & $1,4,5,6,6,8,10,11,12,13,14$ & $1,4,5,6,6,8,10,12,13,14$ & 19 & 7 & 10 & 13 \\
\hline 9 & $1,2,3,4,5,5,6,7,7,9,13,14$ & $8,9,13,14$ & $9,13,14$ & 7 & 1 & 4 & 10 \\
\hline 10 & $1,2,3,4,7,7,8,10,12,13,14$ & $3,5,6,7,7,8,10,12,13,14$ & $3,7,8,10,12,13,14$ & 16 & 4 & 9 & 10 \\
\hline 11 & $1,2,3,7,8,11,12,13,14$ & $1,6,7,11,14$ & $1,7,11,14$ & 9 & 2 & 5 & 9 \\
\hline 12 & $1,2,3,4,5,6,6,8,10,12,13,14$ & $1,3,5,6,8,8,10,11,12,14$ & $1,3,5,6,8,10,12,14$ & 17 & 5 & 9 & 11 \\
\hline 13 & $1,2,3,4,5,6,6,7,8,9,10,13,14$ & $1,2,3,8,9,10,11,12,13,14$ & $1,2,3,8,9,10,13,14$ & 18 & 6 & 10 & 12 \\
\hline 14 & $1,2,3,4,5,6,6,7,8,9,10,11,12,13,14$ & $1,2,3,5,8,9,10,11,12,13,14$ & $1,2,3,5,8,9,10,11,12,13,14$ & 22 & 8 & 11 & 14 \\
\hline
\end{tabular}

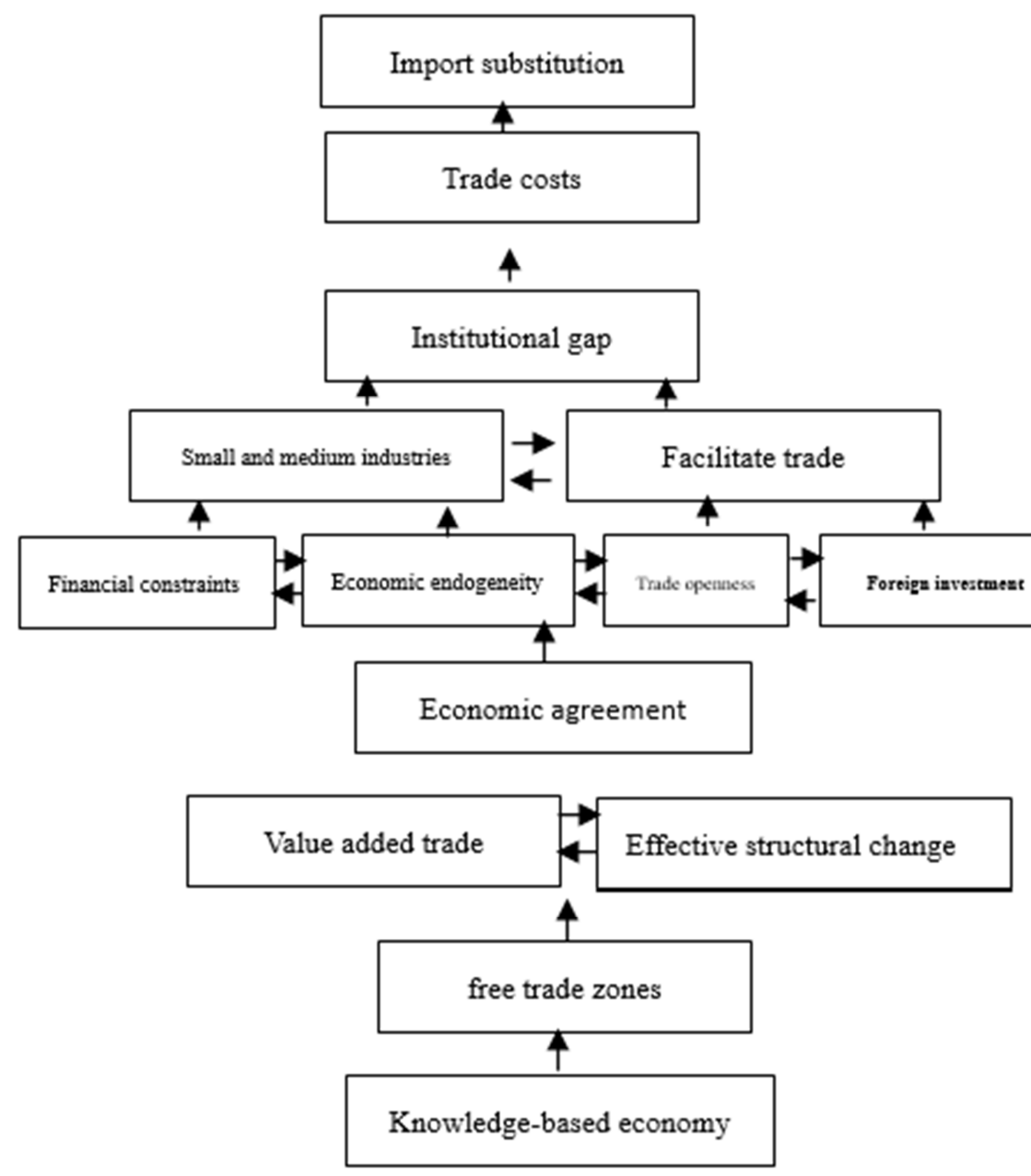

Figure 1. ISM-based model for foreign trade components.

\subsection{Drawing Pattern}

In this step, the initial matrix including the transition (Figure 2) is developed using the final achievement matrix and the split surfaces using the nodes to represent the enablers and arrows for the relationships between them.

\subsection{Build a Model Based on an Interpretive Structural Model}

The final diagram is transformed by replacing the 
constructor nodes with the statements as shown in Figure 1. The ISM model provides information about the hierarchy of variables for the successful implementation of foreign trade.

\subsection{Investigating Conceptual Contradiction}

Finally, the ISM model is reviewed for conceptual inconsistency.

\subsection{Classification and Analysis (MICMAC)}

The purpose of MICMAC is to examine driving power and the dependence of listed factors. Based on these abilities, factors are divided into four clusters [42].

1. Autonomous variables 2. Dependent variables 3 . Communication variables 4 . Independent variables

Autonomous factors: These factors have both driving power and poor dependence. 2. Dependent factors: This category includes factors that have weak drive power but strong dependency power. 3 connecting factors: It has strong driving power as well as strong dependence. They are also unstable. Any action on them will affect others as well as feedback. 4. Independent factors: include independent factors with strong driving power and weak dependence [10].

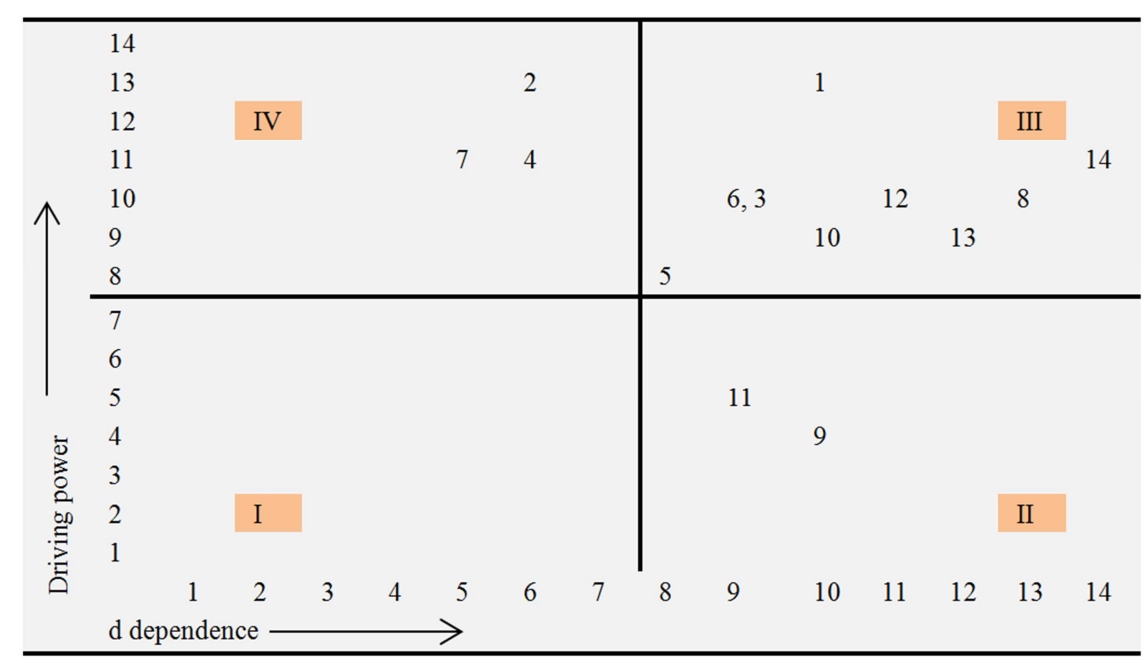

Figure 2. Driving power - dependence table. The example for this table.

\section{Conclusion}

Advancing the development of foreign trade requires constant review of effective strategies and components in this field. Foreign trade policies are constantly changing. Therefore, countries need to know what components of development should be addressed, which factors need more attention. The ISM Model (Figure 1) and the Driver-Power Dependency Chart (Figure 2) help countries gain more insight into foreign trade operations.

From the ISM model, it can be seen that the knowledge-based economy is at the end of the model and is therefore important and can be considered as a key variable in Iran's foreign trade. Dependency-driving diagram presents similar observations. Knowledge-based variable is classified as an independent factor that shows high driving power. This factor affects other factors. It seems to be one of the essential requirements for Changing the context and making it conducive to achieving a knowledge-based economy is diversifying the economy and reducing the degree of dependence on oil.

The next level of the ISM model hierarchy includes the free trade zone variable. In fact, the second key factor of the model is the relationship between knowledge-based economy and free trade zones. It affects two other important components. Free trade zones will provide a platform for interaction with countries in order to absorb technology, technology and financial resources, part of the structural problems and competitiveness of production. 8), two basic variables that are related to each other. In other words, effective structural change leads to the production of high value-added goods. (2) is shown as an independent variable and high penetration power.

The next level of the ISM model hierarchy includes the regional economic agreement (13). In the last ten years, countries have moved towards concluding bilateral regional agreements, so it is necessary for Iran to develop a comprehensive plan for 15 neighboring countries (especially Iraq). It seems that these variables form the basic body of the model. They formed. Figure 3 shows the two variables of financial constraint and economic endogeneity in the classification of independent variables and high influence. The placement of these variables is shown in Figures 2 and 3. Improving the business environment and empowering domestic products are among them. Lack of a coherent and integrated financing policy is one of the main challenges of the Iranian economy. Therefore, the need for a comprehensive review of the two-way relationship between production and financing is necessary.

The next level of the ISM model in Figure 1, includes the variables of medium and small industries and trade facilitation, which is affected by the lower variables of the model, which in Figure 2, except for the variables of communication (6), (10). Other variables such as institutional gap (5), trade costs (11) and finally import substitution (9) are seen as the most 
dependent variables of the model. The formulation and implementation of foreign trade policies with high driving power, these variables affect. And change in accordance with macroeconomic policies.

Therefore, the parameters and relationships of the ISM model in this research should be examined in the future. Theoretically, this research is done in three stages: first, it identifies it, provides important variables for the successful implementation of foreign trade and provides a brief description of them. Second, it presents a model based on The ISM demonstrates the hierarchy and relationships within variables that can be used as a pure launching pad to take appropriate action. In addition to the resources, the findings of this study help countries decide how to be unique and make the existing capabilities of the existing system competitive. With regional turmoil facing unprecedented speed and likely to continue, it is imperative that Iran's economic managers use the box of thinking in the future to turn mitigation strategies and barriers into superior opportunities. It will be useful for Iran. Iran's economy, especially foreign trade, needs to identify the main and strategic obstacles and develop a comprehensive plan to solve them.

In this study, 14 variables were identified as effective and challenging components for the improvement and development of Iran's foreign trade. One of the strengths of this article is its limitations in identifying experts and gathering information, access to economic and business experts for interviews was difficult, as well as expert opinions and generalizability. It will vary in terms of time and economic situation of countries.

\section{Suggestions}

Considering the research findings, suggestions for future researchers are recommended to strengthen and continue the development of Iran's trade relations with Iraq as well as the countries of the region. This study considered Iraq, considering 15 neighboring countries of Iran, which have high economic capacity and export opportunities, as well as the development and deepening of economic and trade relations, so to identify and existing themes with countries in the region separately. To be studied and examined. Knowledge-based economy, free trade zones, effective structural change and value-added trade were identified as key factors influencing other model factors. Therefore, in order to deeply explain and identify operational solutions for the above components, it should be studied separately.

\section{References}

[1] Al-Tajai, I \& Pourbaqer, Z (2014). Investigating the Orientation of Iran's Foreign Trade Policies. Quarterly Journal of Financial and Economic Policies, 7 (2), 109-134. J. Clerk Maxwell, A Treatise on Electricity and Magnetism, 3rd ed., vol. 2. Oxford: Clarendon, 1892, pp. 68-73.

[2] Sohrabi, R, Rostami, M. (2018). Identifying and ranking the factors affecting the promotion of dynamic capabilities in small and medium industries (Case study of Kurdistan industries). Using model (ISM) and model. (DEMATEL) Business Research Journal, 22 (88), 155-179. K. Elissa, "Title of paper if known," unpublished.

[3] Abubakr, S., \& Esposito, F. (2012). Bank concentration and financial constraints on firm investment in UK. Studies in Economics and Finance, 29 (1), 11-25.

[4] Álvarez, I. C., Barbero, J., Rodríguez-Pose, A., \& Zofío, J. L. (2018). Does institutional quality matter for trade? Institutional conditions in a sectoral trade framework. World Development, $103,72-87$.

[5] Bouët, A., Berisha-Krasniqi, V., Estrades, C., \& Laborde, D. (2012). Trade and investment in Latin America and Asia: Perspectives from further integration. Journal of Policy Modeling, 34 (2), 193-210.

[6] Balaguer, J., Florica, T., \& Ripollés, J. (2015). Foreign trade and economic growth in Spain (1900-2012): the role of energy imports. Economia Politica, 32 (3), 359-375.

[7] Chang, A. Y., \& Cheng, Y. T. (2019). Analysis model of the sustainability development of manufacturing small and medium-sized enterprises in Taiwan. Journal of Cleaner Production, 207, 458-473.

[8] Demir, A., Özmen, Ö., \& Rashid, A. (2014). An Estimation of Turkey's Export Loss to Iraq. Procedia-Social and Behavioral Sciences, 150, 1240-1247.

[9] Devadason, E. S., Govindaraju, V. C., \& Mubarik, S. (2018). Defining potentials and barriers to trade in the Malaysia-Chile partnership. International Journal of Emerging Markets, 13 (5), 758-779.

[10] Digalwar, A. K., Mundra, N., Tagalpallewar, A. R., \& Sunnapwar, V. K. (2017). Road Map for The Implementation of Green Manufacturing Practices in Indian Manufacturing Industries.: An ISM approach. Benchmarking: An International Journal, 24 (5).

[11] de Menezes Barboza, R., \& Vasconcelos, G. F. (2019). Measuring the aggregate effects of the Brazilian Development Bank on investment. The North American Journal of Economics and Finance, 47, 223-236.

[12] Ershova, I., \& Ershov, A. (2016). Development of a strategy of import substitution. Procedia Economics and Finance, 39, 620-624.

[13] Farris, D. R. and Sage, A. P. (1975), "On the use of interpretive structural modeling for worth assessment", Computers and Electrical Engineering, Vol. 2 Nos 2/3, pp. 149-174.

[14] Gnangnon, S. K. (2017). Structural economic vulnerability, openness and bilateral development aid flows. Economic Analysis and Policy, 53, 77-95.

[15] Gnangnon, S. K. (2018). Effect of multilateral trade liberalization on foreign direct investment outflows amid structural economic vulnerability in developing countries. Research in International Business and Finance, 45, 15-29.

[16] Gurvich, E. (2016). Institutional constraints and economic development. Russian Journal of Economics, 2 (4), 349-374.

[17] Haraguchi, N., Cheng, C. F. C., \& Smeets, E. (2017). The importance of manufacturing in economic development: Has this changed?. World Development, 93, 293-315. 
[18] Hasan, M. A., Shankar, R., Sarkis, J., Suhail, A. and Asif, S. (2009), "A study of enablers of agile manufacturing", International Journal of Industrial and Systems Engineering, Vol. 4 No. 4, pp. 407-430.

[19] Jokanović, B., Lalic, B., Milovančević, M., Simeunović, N., \& Marković, D. (2017). Economic development evaluation based on science and patents. Physica A: Statistical Mechanics and its Applications, 481, 141-145.

[20] Karam, F., \& Zaki, C. (2018). Why don't MENA countries trade more? The curse of deficient institutions. The Quarterly Review of Economics and Finance.

[21] Kawasaki, K. (2017). Emergent Uncertainty in Regional Integration-Economic Impacts of Alternative RTA Scenarios. National Graduate Institute for Policy Studies, 16-28.

[22] Kikuchi, T., Yanagida, K., \& Vo, H. (2018). The effects of mega-regional trade agreements on Vietnam. Journal of Asian Economics, 55, 4-19.

[23] Kariuki, C. (2015). The determinants of foreign direct investment in the African Union. Journal of Economics, Business and Management, 3 (3), 346-351.

[24] Lee, J. N., Ham, J., \& Choi, B. (2016). Effect of Government Data Openness on a Knowledge-based Economy. Procedia Computer Science, 91, 158-167.

[25] Lincoln, W. F., \& McCallum, A. H. (2018). The rise of exporting by US firms. European Economic Review, 102, 280-297.

[26] Lee, D., \& Hudson, D. (2004). The old and new significance of political economy in diplomacy. Review of International Studies, 30 (3), 343-360.

[27] Márquez-Ramos, L., Martínez-Zarzoso, I., \& Suárez-Burguet, C. (2011). Trade Policy versus Trade Facilitation: An Application Using'Good Old'OLS. Economics Discussion Paper, (2011-38).

[28] Mau, V. (2017). Lessons in stabilization and prospects for growth: Russia's economic policy in 20161. The economic state of the Baltic Sea region, 36.

[29] Mandal, A., \& Deshmukh, S. G. (1994). Vendor selection using interpretive structural modelling (ISM). International Journal of Operations \& Production Management, 14 (6), 52-59.

[30] Marconi, N., de Borja Reis, C. F., \& de Araújo, E. C. (2016). Manufacturing and economic development: The actuality of Kaldor's first and second laws. Structural Change and Economic Dynamics, 37, 75-89.

[31] Mourao, P. R. (2018). What is China seeking from Africa? An analysis of the economic and political determinants of Chinese Outward Foreign Direct Investment based on Stochastic Frontier Models. China Economic Review, 48, 258-268.

[32] MA, Y., QU, B., \& ZHANG, Y. (2011). Institutional Barriers, Trade, and Product Complexity: Empirical Evidence at the Firm Level.

[33] Otsuki, T., Honda, K., \& Wilson, J. S. (2013). Trade facilitation in South Asia. South Asian Journal of Global Business Research, 2 (2), 172-190.

[34] Pan, W. H., \& Ngo, X. T. (2016). Endogenous growth theory and regional performance: The moderating effects of special economic zones. Communist and Post-Communist Studies, 49 (2), 113-12

[35] Rodrigues, M. (2010). Import substitution and economic growth. Journal of Monetary Economics, 57 (2), 175-188.

[36] Simachev, Y., \& Kuzyk, M. (2018). Industrial Development, Structural Changes, and Industrial Policy in Russia. In Exploring the Future of Russia's Economy and Markets: Towards Sustainable Economic Development (pp. 69-106). Emerald Publishing Limited.

[37] Song, M., Wang, J., Wang, S., \& Zhao, D. (2018). Knowledge accumulation, development potential and efficiency evaluation: an example using the Hainan free trade zone. Journal of Knowledge Management.

[38] Veselá, D., \& Klimová, K. (2014). Knowledge-based economy vs. creative economy. Procedia-Social and Behavioral Sciences, $141,413-417$.

[39] Szirmai, A., \& Verspagen, B. (2015). Manufacturing and economic growth in developing countries, 1950-2005. Structural Change and Economic Dynamics, 34, 46-59.

[40] Sage, A. (1977). Interpretive structural modeling: methodology for large-scale systems, 91-164.

[41] Talib, F., \& Rahman, Z. (2017). Modeling the barriers of Indian telecom services using ISM and MICMAC approach. Journal of Asia Business Studies, 11 (2), 188-209.

[42] Engel, J., \& Taglioni, D. (2017). The middle-income trap and upgrading along global value chains. Global Value Chain Report, 119-139.

[43] Cumming, D., Deloof, M., Manigart, S., \& Wright, M. (2019). New directions in entrepreneurial finance. Journal of Banking \& Finance, 100, 252-260.

[44] Vu, K. M. (2017). Structural change and economic growth: Empirical evidence and policy insights from Asian economies. Structural Change and Economic Dynamics, 41, 64-77. 